\title{
Short communication: Fluoroquinolone susceptibility of Staphylococcus aureus strains isolated from caprine clinical mastitis in southeast Spain
}

\author{
P. Marín, ${ }^{* 1}$ E. Escudero, ${ }^{*}$ E. Fernández-Varón, ${ }^{*}$ C. M. Cárceles, ${ }^{*}$ J. C. Corrales, $†$ A. Gómez-Martín, $\dagger$ \\ and I. Martínez* \\ *Department of Pharmacology, and \\ †Department of Animal Health, Faculty of Veterinary Medicine, University of Murcia, Campus de Espinardo, 30071-Murcia, Spain
}

\begin{abstract}
The antibiotic susceptibility of 32 strains of Staphylococcus aureus isolated from the mastitic milk of dairy goats was evaluated. The antibiotics tested were 3 fluoroquinolones that have been developed especially for use in veterinary medicine: danofloxacin, marbofloxacin, and orbifloxacin. Minimum inhibitory concentration (MIC) tests were performed according to the microdilution broth method. The $\mathrm{MIC}_{90}$ (concentration at which $90 \%$ inhibition is achieved) values obtained were $0.5,1$, and $1 \mathrm{mg} / \mathrm{L}$ for danofloxacin, marbofloxacin, and orbifloxacin, respectively. Danofloxacin was the most active fluoroquinolone tested against Staph. aureus strains isolated from milk; however, specific testing is required before using these drugs as therapy for the control of clinical mammary infections in goats.
\end{abstract}

Key words: Staphylococcus aureus, fluoroquinolone, mastitis, goat milk

Mastitis, which may be clinical or subclinical, is an important mammary gland disease that is usually caused by bacterial infection. If untreated, it constitutes a serious problem in dairy herds, with considerable economic consequences, mainly because of reduced milk production and discarded milk (Seegers et al., 2003). Although several bacterial pathogens can cause mastitis, Staphylococcus aureus is one of the most important etiologic agents in mastitis of cows, goats, and sheep (Mørk et al., 2005; Aires-de-Sousa et al., 2007). Moreover, Staph. aureus is probably the most important infectious agent because it causes a chronic and deep infection in the mammary glands that is extremely difficult to cure (Miles et al., 1992). The prevalence of Staph. aureus IMI in goats ranged from 5.6 to $17 \%$ in different countries (Silva et al., 2006).

Fluoroquinolones are antimicrobial drugs that generally have very good activity against a broad spectrum

\footnotetext{
Received April 16, 2010.

Accepted August 1, 2010.

${ }^{1}$ Corresponding author: pmarin@um.es
}

of aerobic bacteria, including Pasteurella spp. and mycoplasma (Giles et al., 1991; Gutiérrez and Rodríguez, 1993; Hannan et al., 1997). The main target site for its bactericidal action is the DNA gyrase. This enzyme is required for supercoiling of DNA to facilitate the spatial arrangement of DNA in the bacterial cell. Furthermore, fluoroquinolones have good pharmacological characteristics for using in animal therapy such as large volumes of distribution, low plasma protein binding, and relatively low MIC against susceptible target microorganisms (Brown, 1996). Danofloxacin (DAN), marbofloxacin (MAR), and orbifloxacin (ORB), are relatively new synthetic fluoroquinolone antimicrobial drugs that have been developed especially for use in veterinary medicine, and they could be useful in lactating goats and other lactating species.

Therefore, this study was designed to evaluate the degree of in vitro activity of DAN, MAR, and ORB against 32 Staph. aureus strains isolated from the milk of goats with clinical mastitis in Spain.

Thirty-two Staphylococcus aureus strains were isolated from milk of goats with clinical mastitis in the southeastern region of Spain. Twenty microliters of each sample was plated on blood agar plates $(5 \%$ washed sheep erythrocytes). The plates were incubated aerobically at $37^{\circ} \mathrm{C}$ and examined at 24,48 , and $72 \mathrm{~h}$. Bacteria with target hemolysis were identified according to the recommendations of the National Mastitis Council (Harmon et al., 1990). Specific identification of Staph. aureus was made using commercial latex agglutination kit (Staphytec Plus, Oxoid, Basingstoke, UK). The strains were stored at $-80^{\circ} \mathrm{C}$ in a nutrient broth enriched with $15 \%$ glycerol.

The antibiotics selected for the study were DAN, MAR, and ORB; DAN and MAR were provided by the manufacturer (Riedel-de Haën, Seelze, Germany), and ORB was obtained in pure form from Schering Plough Corp. (Kenilworth, NJ). Antibiotics were dissolved in suitable solvents to make stock solutions and then diluted in sterile distilled water according to the methods recommended by the Clinical and Laboratory Standards Institute (CLSI, 2009). 
Table 1. Minimal inhibitory concentrations of danofloxacin (DAN), marbofloxacin (MAR), and orbifloxacin (ORB) on Staphylococcus aureus strains isolated from mastitic goat milk $(\mathrm{n}=32)$, as well as $\mathrm{MIC}_{50}$ and $\mathrm{MIC}_{90}$ values and minimum and maximum MIC values (range)

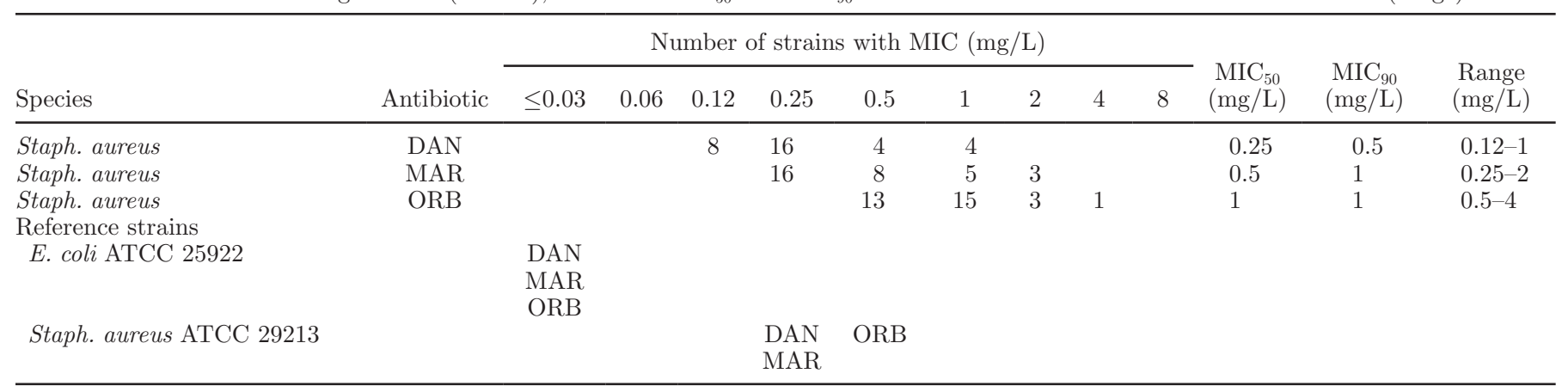

Minimum inhibitory concentration tests were performed according to the microdilution broth method as recommended by CLSI (2009) using U-bottomed, 96-well microtiter plates. Serial 2-fold dilutions of the antimicrobial agents were prepared starting from the stock solution of each drug. Concentrations of DAN, $\mathrm{MAR}$, and $\mathrm{ORB}$ ranging from 0.03 to $128 \mathrm{mg} / \mathrm{L}$ were used.

Inocula were prepared by diluting an overnight $\mathrm{Mu}$ eller-Hinton broth culture in buffered saline solution to a density of 0.5 on the McFarland turbidity scale and finally diluting again 40-fold before testing.

The MIC was defined as the lowest concentration of antibiotic at which the bacterial growth was completely inhibited. The reference strains Staph. aureus (ATCC 29213) and Escherichia coli (ATCC 25922) were from Colección Española de cultivos tipo (CECT; Valencia, Spain) and used as controls for each plate.

Numerous data are available in the literature on the susceptibility to antimicrobial agents of Staph. aureus strains isolated from milk of dairy cows (Pengov and Ceru, 2003; Tikofsky et al., 2003); however, only scant data exist for dairy goats. The MIC values of the selected antibiotics are shown in Table 1, as well as MIC values of these drugs that inhibited 50 and $90 \%$ of the isolates $\left(\mathbf{M I C} \mathbf{C}_{50}\right.$ and $\mathbf{M I C} \mathbf{C}_{90}$, respectively), and the minimum and maximum MIC values (range).

According to the susceptibility and resistance breakpoints, a strain is considered resistant when the MIC is $\geq 4 \mathrm{mg} / \mathrm{L}$ for MAR, and MIC is $\geq 8 \mathrm{mg} / \mathrm{L}$ for DAN and ORB (CLSI, 2008). None of the strains tested in the current study were resistant to these antibiotics. The most active fluoroquinolone tested against Staph. aureus strains isolated from milk was DAN $\left(\mathrm{MIC}_{90}=\right.$ $0.5 \mathrm{mg} / \mathrm{L})$. A correlation between the MIC of DAN, MAR, and ORB was observed for each isolate tested.

The $\mathrm{MIC}_{90}$ values reported in previous studies for ORB against Staphylococcus intermedius isolated from canine infections $\left(\mathrm{MIC}_{90}=1 \mathrm{mg} / \mathrm{L}\right.$; Ganiere et al., 2004) and Staph. aureus isolated from rabbits $\left(\mathrm{MIC}_{90}=2 \mathrm{mg} / \mathrm{L}\right.$;
Marín et al., 2008) were similar to those obtained in the present study. Grobbel et al. (2007) reported a $\mathrm{MIC}_{50}$ $=0.25 \mathrm{mg} / \mathrm{L}$ for MAR against Staph. aureus strains isolated from bovine mastitis. This value is lower than the MIC obtained in this work $\left(\mathrm{MIC}_{50}=0.5 \mathrm{mg} / \mathrm{L}\right)$. Moreover, lower values of $\mathrm{MIC}_{90}$ for MAR than in the present study were obtained by Schneider et al. (2004) against Staph. aureus isolated from bovine mastitic milk. Danofloxacin showed good activity against Staph. aureus in this work, and similar values were obtained by Grobbel et al. (2007). However, Fernández-Varón et al. (2007) obtained higher $\mathrm{MIC}_{90}$ values $\left(\mathrm{MIC}_{90}=4\right.$ $\mathrm{mg} / \mathrm{L}$ ) against Staph. aureus isolated from rabbits.

Broad-spectrum antimicrobial drugs such as fluoroquinolones have been recommended and used to treat mastitis (Dosogne et al., 2002). Because the fluoroquinolones are relatively new antimicrobial agents, extensive research is needed to develop and implement appropriate specific dosing regimens that can maximize their clinical efficacy for use in production animals and reduce the risk of selection of resistant pathogens, particularly because these drugs are used for the treatment of multidrug-resistant infection in humans (Walker, 2000).

The ratios $\mathrm{C}_{\max } / \mathrm{MIC}_{90}$ and $\mathrm{AUC}_{24} / \mathrm{MIC}_{90}$ are the best parameters for predicting the antimicrobial effect of fluoroquinolones, where $\mathrm{C}_{\max }=$ peak or maximum plasma or milk concentration following extravascular administration, and $\mathrm{AUC}_{24}$ = area under the plasma or milk concentration-time curve from 0 to $24 \mathrm{~h}$. Previous investigations have shown that for fluoroquinolones, $\mathrm{C}_{\max } / \mathrm{MIC}_{90}>3$ produced $99 \%$ reduction in bacterial counts and $\mathrm{C}_{\max } / \mathrm{MIC}_{90}$ of $\geq 8$ prevented the emergence of resistant organisms (Craig, 1998). Furthermore, $\mathrm{AUC}_{24} /$ $\mathrm{MIC}_{90}>100 \mathrm{~h}$ should be achieved to give maximum clinical and bacteriological efficacy (Turnidge, 1999). Therefore, if we take into account milk AUC and $\mathrm{C}_{\max }$ parameters from a pharmacokinetic study with ORB in dairy goats (Marín et al., 2007), the optimal values of $\mathrm{C}_{\max } / \mathrm{MIC}_{90}>8$ and $\mathrm{AUC}_{24} / \mathrm{MIC}_{90}>100 \mathrm{~h}$ are not 
reached. However, it must be noted that the numerical values of $\mathrm{C}_{\max } / \mathrm{MIC}_{90}$ and $\mathrm{AUC}_{24} / \mathrm{MIC}_{90}$, used as surrogate markers to predict optimal therapeutic outcomes, have been generated from experimental infections in laboratory animals or in human clinical trials (Toutain and Lees, 2004), and may not be applicable to goat infections or to animal infections in general. In fact, Lees and Shojaee Aliabadi (2002) studied, in ex vivo experiments, the ratio of AUC/MIC producing bacteriostasis, bactericidal activity, and elimination of bacteria with different fluoroquinolones and concluded, in all cases, that the surrogate markers for cattle, sheep, goat, and camel were lower than 100 to $125 \mathrm{~h}$. For example, DAN was effective in terms of bacteriological results, milk production, and both systemic and local signs when it was used in the treatment of induced acute E. coli bovine mastitis (Poutrel et al., 2008). Therefore, although their pharmacokinetic/pharmacodynamic indices are not the optimum described in the literature, these antibiotics could be useful for treating mammary infections in goats. However, it is necessary to first carry out clinical efficacy studies in order to determine the proper dosage regimens. We conclude that DAN, MAR, and ORB, fluoroquinolone antimicrobial drugs developed especially for use in veterinary medicine, showed good in vitro activity against Staph. aureus strains isolated from mastitic goat milk.

\section{ACKNOWLEDGMENTS}

This work was supported by the Ministerio de Ciencia e Innovación of Spain (Madrid, Spain; AGL2008-04430/ GAN). Isolation of Staph. aureus strain was supported by the project AGL2009-09128.

\section{REFERENCES}

Aires-de-Sousa, M., C. E. S. R. Parente, O. Vieira-da-Mota, I. C. F. Bonna, D. A. Silva, and H. Lencastre. 2007. Characterization of Staphylococcus aureus isolates from buffalo, bovine, ovine, and caprine milk samples collected in Rio de Janeiro State, Brazil. Appl. Environ. Microbiol. 73:3845-3849.

Brown, S. A. 1996. Fluoroquinolones in animal health. J. Vet. Pharmacol. Ther. 19:1-14.

CLSI (Clinical and Laboratory Standards Institute). 2008. Development of in vitro susceptibility testing criteria and quality control parameters for veterinary antimicrobial agents; approved guideline, third ed. NCCLS document M37-A3. Clinical and Laboratory Standards Institute, Wayne, PA.

CLSI (Clinical and Laboratory Standards Institute). 2009. Methods for dilution antimicrobial susceptibility test for bacteria that grow aerobically; approved standard, eighth ed. NCCLS document M07A8. Clinical and Laboratory Standards Institute, Wayne, PA.

Craig, W. A. 1998. Pharmacokinetic/pharmacodynamic parameters: Rationale for antibacterial dosing of mice and men. Clin. Infect. Dis. $26: 1-10$.

Dosogne, H., E. Meyer, A. Sturk, J. van Loon, A. M. Massart-Leën, and C. Burvenich. 2002. Effect of enrofloxacin treatment on plasma endotoxin during bovine Escherichia coli mastitis. Inflamm. Res. 51:201-205.
Fernández-Varón, E., P. Marín, E. Escudero, D. Vancraeynest, and C. M. Cárceles. 2007. Pharmacokinetic-pharmacodynamic integration of danofloxacin after intravenous, subcutaneous and intramuscular administration to rabbits. J. Vet. Pharmacol. Ther. 30:18-24.

Ganiere, J. P., C. Medaille, and F. Etore. 2004. In vitro antimicrobial activity of orbifloxacin against Staphylococcus intermedius isolated from canine skin and ear infections. Res. Vet. Sci. 77:67-71.

Giles, C. J., R. A. Magonigle, W. T. R. Grimshaw, A. C. Tanner, J. E. Risk, M. J. Lynch, and J. R. Rice. 1991. Clinical pharmacokinetics of parenterally administered danofloxacin in cattle. J. Vet. Pharmacol. Ther. 14:400-410.

Grobbel, M., A. Lübke-Becker, L. H. Wieler, R. Froyman, S. Friederichs, and S. Filios. 2007. Comparative quantification of the in vitro activity of veterinary fluoroquinolones. Vet. Microbiol. 124:73-81.

Gutiérrez, C. B., and E. F. Rodríguez. 1993. In vitro susceptibility of Pasteurella multocida subspecies multocida strains isolated from swine to 42 antimicrobial agents. Zentralbl. Bakteriol. 270:387-393.

Hannan, P. C. T., G. D. Windsor, A. Jong, N. Schmeer, and M. Stegemann. 1997. Comparative susceptibilities of various animalpathogenic mycoplasmas to fluoroquinolones. Antimicrob. Agents Chemother. 41:2037-2040.

Harmon, R. J., R. J. Eberhart, D. E. Jasper, and B. E. Langlois. 1990. Microbiological Procedures for the Diagnosis of Bovine Udder Infection. 3rd ed. National Mastitis Council Inc., Arlington, VA.

Lees, P., and F. Shojaee Aliabadi. 2002. Rational dosing of antimicrobial drugs: Animals versus human. Int. J. Antimicrob. Agents 19:269-284.

Marín, P., E. Escudero, E. Fernández-Varón, and C. M. Cárceles. 2007. Pharmacokinetics and milk penetration of orbifloxacin after intravenous, subcutaneous and intramuscular administration to lactating goats. J. Dairy Sci. 90:4219-4225.

Marín, P., E. Fernández-Varón, E. Escudero, D. Vancraeynest, and C. M. Cárceles. 2008. Pharmacokinetic-pharmacodynamic integration of orbifloxacin in rabbits after intravenous, subcutaneous and intramuscular administration. J. Vet. Pharmacol. Ther. 31:77-82.

Miles, H., W. Lesser, and P. Sears. 1992. The economic implications of bioengineered mastitis control. J. Dairy Sci. 75:596-605.

Mørk, T., T. Tollersrud, B. Kvitle, H. J. Jørgensen, and S. Waage. 2005. Comparison of Staphylococcus aureus genotypes recovered from cases of bovine, ovine, and caprine mastitis. J. Clin. Microbiol. 43:3979-3984.

Pengov, A., and S. Ceru. 2003. Antimicrobial drug susceptibility of Staphylococcus aureus strains isolated from bovine and ovine mammary glands. J. Dairy Sci. 86:3157-3163.

Poutrel, B., M. R. Stegemann, O. Roy, F. Pothier, N. Tilt, and M. Payne-Johnson. 2008. Evaluation of the efficacy of systemic danofloxacin in the treatment of induced acute Escherichia coli bovine mastitis. J. Dairy Res. 75:310-318.

Schneider, M., M. Vallé, F. Woehrlé, and B. Boisramé. 2004. Pharmacokinetics of marbofloxacin in lactating cows after repeated intramuscular administrations and pharmacodynamics against mastitis isolated strains. J. Dairy Sci. 87:202-211.

Seegers, H., C. Fourichon, and F. Beaudeau. 2003. Production effects related to mastitis and mastitis economics in dairy cattle herds. Vet. Res. 34:475-491.

Silva, E. R., J. U. Boechat, and N. Silva. 2006. Coagulase gene polymorphism of Staphylococcus aureus isolated from goat mastitis in Brazilian dairy herds. Lett. Appl. Microbiol. 42:30-34.

Tikofsky, L. L., J. W. Barlow, C. Santisteban, and Y. H. Schukken. 2003. A comparison of antimicrobial susceptibility patterns for Staphylococcus aureus in organic and conventional dairy herds. Microb. Drug Resist. 9:S39-S45.

Toutain, P. L., and P. Lees. 2004. Integration and modelling of pharmacokinetic and pharmacodynamic data to optimise dosage regimens in veterinary medicine. J. Vet. Pharmacol. Ther. 27:467-477.

Turnidge, J. 1999. Pharmacokinetics and pharmacodynamics of fluoroquinolones. Drugs 58:29-36.

Walker, R. D. 2000. Fluoroquinolones. Pages 315-338 in Antimicrobial Therapy in Veterinary Medicine. 3rd ed. J. F. Prescott, J. D. Baggot, and R. D. Walker. Iowa State University Press, Ames. 